University of Pittsburgh Cancer Institute, Pittsburgh, PA

Published online ahead of print at www.jco.org on September 8, 2015

Supported by National Cancer Institute Grant No. P50-CA097190 and National Institute of Dental and Craniofacial Research Grant No. R01-DE019727.

Author's disclosures of potential conflicts of interest are found in the article online at www.jco.org. Author contributions are found at the end of this article.

Corresponding author: Robert L. Ferris, MD, PhD, Hillman Cancer Center Research Pavilion, 5117 Centre Ave, Room 2.26b, Pittsburgh, PA 152131863; e-mail: ferrisrl@upmc.edu.

(C) 2015 by American Society of Clinical Oncology

0732-183X/15/3329w-3293w/\$20.00

DOI: 10.1200/JCO.2015.61.1509

\title{
Immunology and Immunotherapy of Head and Neck Cancer
}

\author{
Robert L. Ferris
}

$\begin{array}{llllllll}\text { A } & \text { B } & \text { S } & \text { T } & \text { R } & \text { A } & \text { C } & \text { T }\end{array}$

The immune system plays a key role in the development, establishment, and progression of head and neck squamous cell carcinoma (HNSCC). A greater understanding of the dysregulation and evasion of the immune system in the evolution and progression of HNSCC provides the basis for improved therapies and outcomes for patients. HNSCC cells evade the host immune system through manipulation of their own immunogenicity, production of immunosuppressive mediators, and promotion of immunomodulatory cell types. Through the tumor's influence on the microenvironment, the immune system can be exploited to promote metastasis, angiogenesis, and growth. This article provides a brief overview of key components of the immune infiltrating cells in the tumor microenvironment, reviewing immunological principles related to head and neck cancer, including the concept of cancer immunosurveillance and immune escape. Current immunotherapeutic strategies and emerging results from ongoing clinical trials are presented.

\section{J Clin Oncol 33:3293-3304. (C) 2015 by American Society of Clinical Oncology}

\section{INTRODUCTION}

Cancer immunotherapy is based on the premise that tumors can be recognized as foreign rather than as self and can be effectively attacked by an activated immune system. A greater understanding of the dysregulation and evasion of the immune system in the development and evolution of head and neck squamous cell carcinoma (HNSCC) should lead to improved therapies and outcomes for patients. Recently, there has been a renaissance in the idea that nascent premalignant cells are destroyed by the immune system before tumor formation can occur (termed immune surveillance). Derangements in the immune system or alterations in the transformed cells may allow immune escape, which then enables the cancer to manifest. Tumors themselves produce cytokines, such as transforming growth factor- $\beta$ (TGF- $\beta$ ), interleukin (IL)-6, and IL-10, which suppress cell-mediated antitumor immunity while activating STAT1 (signal transducer and activator of transcription 1) suppression. ${ }^{1,2}$ Inflammatory transcription factors, such as NF- $\kappa \mathrm{B}$ (nuclear factor $\kappa$-light chain-enhancer of activated B cells) and STAT3, are aberrantly activated in tumor cells and are intensively studied as possible targets for therapeutic intervention.

Tumor progression depends on acquisition of traits that allow cancer cells to evade immune surveillance and an effective immune response. HNSCC is an immunosuppressive disease, with lower absolute lymphocyte counts than those found in healthy subjects, ${ }^{3}$ impaired natural killer $(\mathrm{NK})$ - cell activity, ${ }^{4,5}$ and poor antigen-presenting function. ${ }^{6,7}$ Impairment of tumor-infiltrating $\mathrm{T}$ lymphocytes has also been reported in HNSCC and other cancers, ${ }^{8,9}$ with a strong impact on clinical outcome. ${ }^{10}$ In addition, suppressive regulatory $\mathrm{T}$ cells (Tregs) have been linked to HNSCC tumor progression. Tregs secrete suppressive cytokines such as TGF- $\beta$ and IL-10, express cytotoxic T lymphocyte-associated protein 4 (CTLA-4), and correlate with tumor progression. ${ }^{11}$ Therefore, immunomodulatory therapies that overcome immune suppressive signals in patients with HNSCC have therapeutic promise. These include cancer vaccines using tumor peptide antigens, or viral, bacterial, and DNA-based vectors-as well as tumor antigen-specific monoclonal antibodies (moAbs). The recent clinical efficacy of US Food and Drug Administration-approved moAbs targeting immune checkpoint receptors, including antiCTLA-4 and anti-programmed death-1 (anti-PD-1), provide further promise for patient benefit from immunomodulatory therapies as positive clinical data emerge.

\section{CANCER IMMUNOSURVEILLANCE} AND IMMUNOEDITING

The idea of immune system control of malignant cells was first proposed by Ehrlich in 1908. The cancer immunosurveillance hypothesis was introduced 


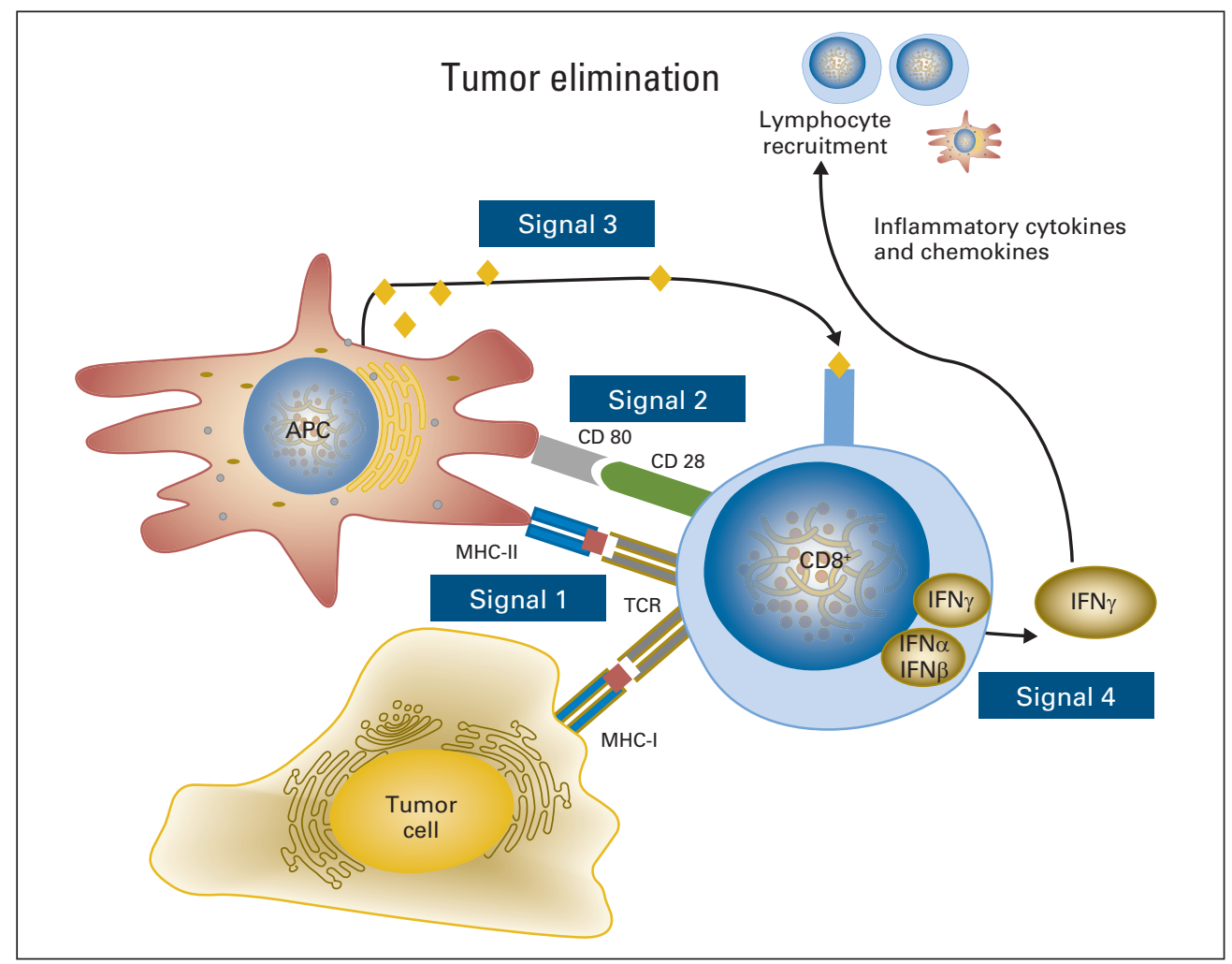

Fig 1. Immune escape from each step required for the development of strong antitumor immunity. Signal 1 represents TCR:HLA-peptide antigen interactions, Signal 2 represents co-stimulatory (or co-inhibitory) signals, Signal 3 indicates cytokine secretion, which may be proinflammatory, type 1 (Th1) antitumor mediators, or tumor-permissing type 2 (Th2) cytokines. Signal 4 represents cell extrinsic attracting chemokine signals to recruit cellular immune populations into the tumor microenvironment and augment/amplify or suppress antitumor immunity.

about 50 years later by Burnet and Thomas, who suggested that tumor cells must have antigens recognizably different from normal cells, and therefore, have the potential for immune clearance. Conflicting experimental results led many to abandon the idea of cancer immunosurveillance for several decades, until several key discoveries led to a revival of the hypothesis. First, in the 1970s, was the discovery of the NK cell by Herbermann, which seemed to provide innate immune protection from tumor. ${ }^{12}$ The discovery of interferon-gamma (IFN- $\gamma$ ) and its proapoptotic effect on tumor growth gave additional support to the potential for immune clearance of cancer cells. ${ }^{13,14}$ Mice with genetically induced immunodeficiency were found to be more susceptible to both spontaneous and chemically induced tumors. In immunodeficient patients with HIV-1 infection, a higher risk of human papillomavirus (HPV) -associated head and neck cancer

\begin{tabular}{|l}
\hline Table 1. Mechanisms of Immune Escape in HNSCC \\
\hline $\begin{array}{c}\text { Mechanism } \\
\text { Development of T-cell tolerance to persistent HPV infection, or } \\
\text { overexpressed/mutated antigens } \\
\text { Production of low genome copy numbers in the basal layer of the } \\
\text { epithelium } \\
\text { Increased PD-L1 expression in HPV-positive tumors and increased PD-1 } \\
\text { expression in cytotoxic T lymphocytes } \\
\text { Downregulation of interferon regulatory factors and activated STAT1 } \\
\text { Inhibition of inflammatory cytokines and transcription factors } \\
\text { Downregulation or mutation of HLA class I and antigen-processing } \\
\text { machinery components } \\
\text { Abbreviations: HNSCC, head and neck squamous cell carcinoma; HPV, } \\
\text { human papillomavirus; PD-1, programmed death-1; PD-L1, programmed } \\
\text { death-1 ligand; STAT1, signal transducer and activator of transcription 1. }\end{array}$ \\
\hline
\end{tabular}

(HNC) has been suggested. ${ }^{15,16}$ In addition, pharmacologically immunosuppressed organ transplant recipients demonstrate increased risk of many tumors with no known viral etiology, such as lung, head and neck, ${ }^{17}$ pancreatic, endocrine, colon, and melanoma tumors. ${ }^{18}$ Cancer immunoediting suggests a dynamic evolutionary progress whereby immune surveillance of cancers provides selective pressure on tumor cells and negatively selects for cells that can evade the immune system. ${ }^{19}$ Thus, successful tumor formation occurs only after the cancer has discovered a means by which it can evade the immune system.

\section{IMMUNE ESCAPE AND IMMUNOSUPPRESSION IN HNC}

To establish effective immunotherapies, understanding the different pathways of tumor immune evasion is necessary. First, HNSCC cells reduce their inherent immunogenicity (Table 1), and second, they actively suppress signals 1-4 of the antitumor immune response (Fig 1). A key component for the immune system's recognition of different or altered cells is the human leucocyte antigen (HLA) complex, which presents processed tumor antigenic peptides to T lymphocytes. ${ }^{7} \mathrm{Tu}-$ mor cells can reduce T-cell-mediated recognition by altering HLA class I expression. Recently, mutations in specific HLA alleles, $\beta-2$ microglobulin, and antigen processing machinery (APM) components have been observed in large-scale, next-generation HNSCC sequencing efforts, such as The Cancer Genome Atlas, ${ }^{20}$ paralleling lung cancer mutations. Chromosomal ${ }^{21}$ and regulatory expression defects ${ }^{6}$ in the HLA/APM-encoding genes themselves can cause selective loss of HLA and APM component expression in a substantial fraction of HNSCCs and are correlated with poor prognosis. ${ }^{22,23}$ 


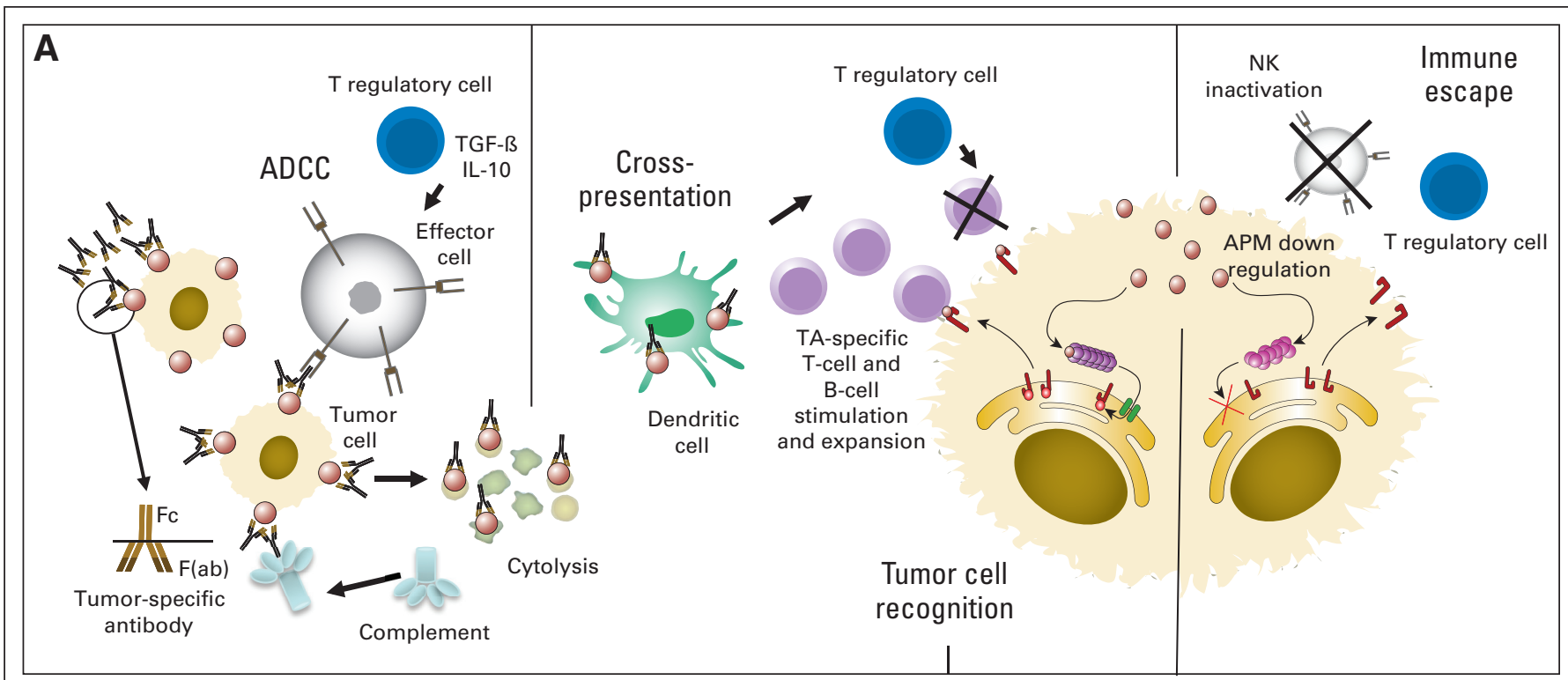

B

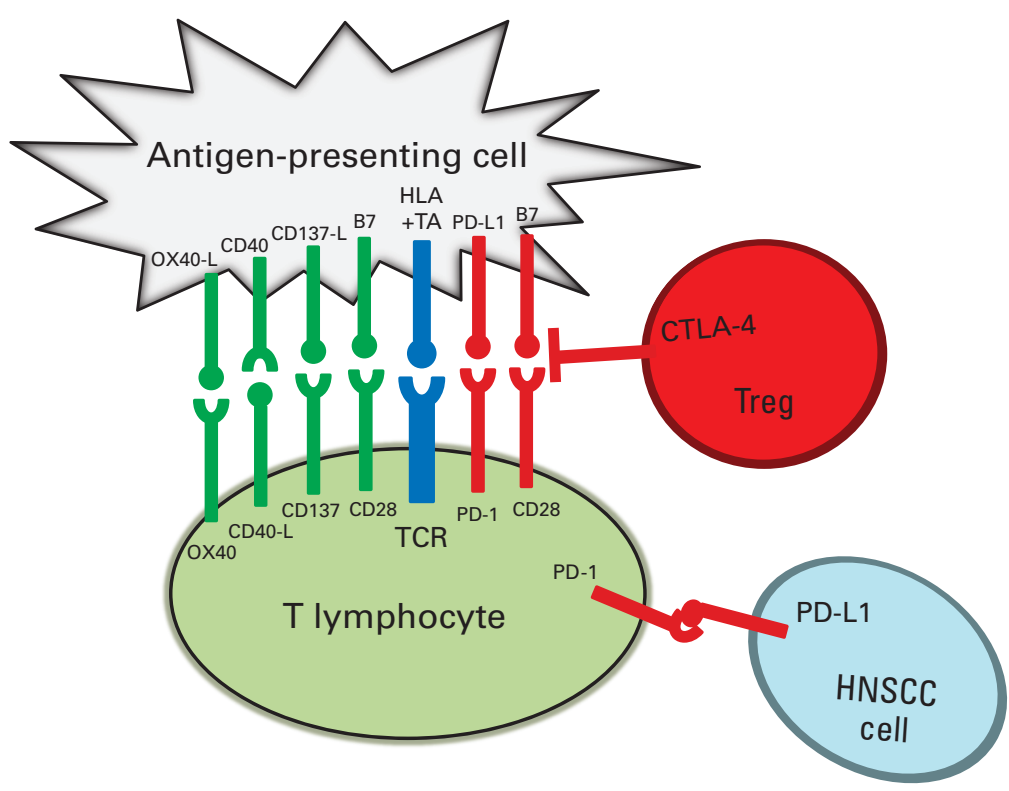

Fig 2. (A) Immune escape pathways at baseline in head and neck squamous cell carcinoma (HNSCC) and during monoclonal antibody therapy. Dysfunction of natural killer (NK) cells, dendritic cells (DCs), and T cells are present, with suppressive cytokines, regulatory T cells (Treg), and myeloid derived suppressor cells. During oncologic therapy, immune escape reversal is portrayed through a proposed model of cellular cascades triggered by activation of NK cells with cetuximab-coated head and neck cancer targets. Cetuximab-mediated NK cell-dependent tumor cell lysis results in the generation of epidermal growth factor receptor-cetuximab immune complexes, which are taken up by DC, processed, and presented to tumor antigen (TA) -specific T cells. Cytotoxic T lymphocytes (CTLs) recognize and eliminate tumor cells. Treg may downregulate NK activity, DC functions, and/or CTL activity, leading to tumor immune escape. In addition, defects in the human leukocyte antigen (HLA) and antigen-processing machinery (APM) component expression in HNSCC cells contribute to tumor escape from CTL recognition. Adapted from Ferris RL, et al: J Clin Oncol 28:4390-4399, 2010. Reprinted with permission from Kansy BA, et al: Curr Otorhinolaryngol Rep 3:63-72, 2015. (B) Costimulatory (green) and coinhibitory (red) signals modify antigen specific stimulation through the T-cell receptor (TCR). Intrinsic suppressive signals on tumor-specific T cells or exerted by suppressive extrinsic Tregs may impair antitumor activity in the tumor microenvironment. Adapted from Bauman JE, et al: Cancer 120:624-632, 2014. ADCC, antibody-dependent cell-mediated cytotoxicity; IL-10, interleukin-10; PD-1, programmed death-1; TGF- $\beta$, transforming growth factor $\beta$.

Cells with complete loss of HLA may evade immune response by T-cell recognition but are a strong trigger for NK-cell activation, as the absence of HLA removes a key inhibitory signal for NK cells (Fig 2). Therefore, tumor cells use multiple mechanisms to realize immunoevasion while avoiding total loss of HLA expression. Endogenous antigens are processed (degraded into peptides) through the cytoplasmic immunoproteosome. Antigenic peptides are transported to the endoplasmic retic- ulum by the transporter associated with antigen processing (TAP1/2) heterodimer of the APM. In the reticulum, they associate with HLA class I heavy chains ${ }^{24}$. HNSCC cells that express HLA I and tumor antigen can still evade T-cell recognition through decreased expression or mutation of APM components but still maintain moderate HLA I expression to avoid recognition by NK cells (Fig 3). In addition to oncogenic epidermal growth factor receptor (EGFR) expression and mitogenic signaling, 


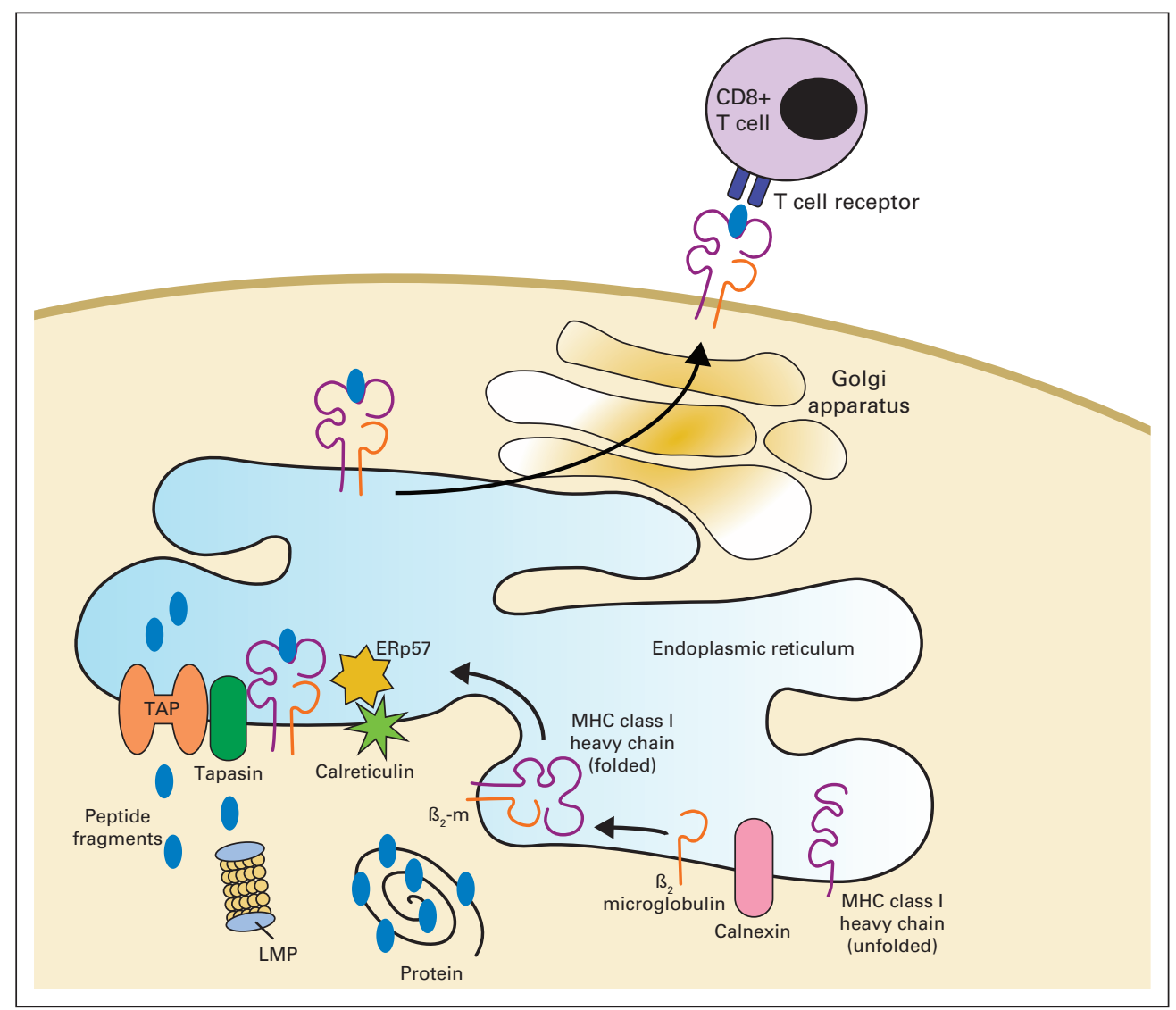

Fig 3. The process of antigen presentation for recognition of tumor cells by the immune system requires fully functional antigen-processing machinery (APM).

immunosuppressive effects may result, including downregulation of HLA, APM components, and STAT1 activation, while leading to suppressive STAT3 signaling, cytokines, and ligands on HNSCC cells.

Another important group of molecules that has emerged from the research is the group of immune checkpoint receptors. As part of the immune system's control mechanisms against overreactive functions during inflammatory responses and to limit autoimmunity, this mechanism can be exploited in the tumor microenvironment. Several receptors have been identified that are expressed on exhausted, dysfunctional lymphocytes, including CTLA-4, lymphocyte-activation gene 3 (LAG-3; CD223), T cell immunoglobulin mucin protein-3 (TIM-3), and PD-1. The ligand for PD-1, PD-L1 (B7-H1, CD274), is upregulated in multiple tumor cell lines, including HNSCC, ${ }^{25}$ and induces a loss of function of cytotoxic T lymphocytes (CTLs). ${ }^{26}$ CTLA- 4 is a member of the B7 receptor family expressed by $\mathrm{CD} 4^{+}, \mathrm{CD}^{+}$, and $\mathrm{Tregs}^{27}$ and competes with CD28 to bind to stimulatory ligands CD80 and CD86. LAG-3 is another receptor that has been shown to enhance Treg function. ${ }^{28}$ TIM-3 as a marker or a mediator for immunosuppression is still being investigated, ${ }^{29}$ but studies have correlated TIM-3 expression levels with poor clinical outcome. ${ }^{30}$ Understanding these mechanisms has facilitated further establishment of immunotherapies, as outlined below.

\section{ESTABLISHMENT OF A CANCER-PROMOTING TUMOR MICROENVIRONMENT}

That some cancers arise at sites of chronic inflammation was first noted by Virchow over a century ago. Infiltration of inflammatory mediators and a complex milieu of cytokines, including TGF- $\beta$, IL-6, IL-10, GM-CSF, IL-1 $\beta$, IL-23, and TNF- $\alpha$, as well as chemokines, which are "chemotactic cytokines," may be exploited by tumor cells. More recent developments link many of those cytokines to the formation of suppressive immune cells such as myeloid-derived suppressor cells (MDSCs), Tregs, tumorassociated macrophages (TAMs), and their effectors, which are exploited and promoted by the tumor microenvironment.

\section{CYTOKINES}

Cytokines, which suppress immune function, are known to be produced by HNSCC cells. ${ }^{31}$ TGF- $\beta$ suppresses NK and T-cell activation and is a key cytokine in the differentiation of Tregs. ${ }^{32}$ IL-6 signals via STAT3 to inhibit dendritic cell (DC) maturation and NK-cell, T-cell, neutrophil, and macrophage activation ${ }^{33}$ and has been correlated with recurrence and survival in HNSCC. ${ }^{34}$ STAT3 is a transcription factor that is also involved in several other immunosuppressive pathways such as IL-10 signaling, ${ }^{35}$ suppression of DCs, ${ }^{36}$ downregulation of IL-12, ${ }^{37}$ and generation of Tregs. ${ }^{38}$ Prostaglandin $\mathrm{E}_{2}$ is a prosurvival, proangiogenic molecule that is produced by many cancers, including HNSCC. ${ }^{39-41}$ Vascular endothelial growth factor, which is primarily thought of as a promoter of angiogenesis, is overexpressed in $90 \%$ of $\mathrm{HNSCCs}^{42}$ and functions to increase the ratio of immature to mature DCs in the tumor microenvironment, which is thought to lead to T-cell dysfunction and inactivation. ${ }^{43}$ Toll-like receptors (TLRs) stimulate the production of proinflammatory cytokines 
such as TNF- $\alpha$, IFN- $\gamma$ with a T-cell-stimulating effect resulting in a type 1 helper response.

CELLULAR IMMUNE COMPONENTS OF THE TUMOR MICROENVIRONMENT: MDSCS, TREGS, AND TAMS

MDSCs are a diverse cellular population of myeloid origin with T-cell suppressive functions. ${ }^{44}$ Initial studies in HNSCC found that MDSCs inhibit activated T cells. Also, MDSCs produce nitric oxide and reactive oxygen species, which interact to catalyze the nitration of the T-cell receptor, which inhibits T-cell receptor and HLA interaction, signaling, and subsequent activation. ${ }^{45}$ Treatments such as antibody depletion, retinoic acid, gemcitabine, and STAT3 blockade, which diminish MDSCs, restore immune surveillance, increase T-cell activation, and improve efficacy of immunotherapy. The basal levels of MDSCs increase with age and may contribute to increased tumor frequency and growth rate increase with age. ${ }^{46}$

A subset of suppressor Tregs that prevent autoimmunity was relatively recently identified. This subpopulation of $\mathrm{CD} 4^{+} \mathrm{T}$ cells also express CD25, ${ }^{47,48}$ CTLA-4 and CD39. Tregs promote cancer progression by causing anergy, apoptosis, and cell cycle arrest of activated $\mathrm{T}$ cells via production of IL-10, TGF- $\beta$, and direct cell-to-cell contact. ${ }^{49}$ They also inhibit the action of DCs, NK cells, and B cells. ${ }^{50}$ In patients with HNSCCs, Tregs are increased in peripheral blood and are more potent among $\mathrm{T}$ cells infiltrating the tumor, resulting in an immunosuppressed state. ${ }^{27,51,52}$ Also, Treg numbers are inversely proportional to DC and $\mathrm{CD}^{+}$T-cell numbers in HNSCC. ${ }^{53,54}$ In addition, Treg frequency is elevated in patients with HNSCC after treatment, indicating that oncologic treatment increases Treg numbers. ${ }^{27}$

TAMs in the tumor microenvironment may be strongly antitumor and possess a so-called M1 phenotype, which is characterized by the production of IFN- $\gamma$ and other type 1 cytokines. Alternatively activated macrophages force a Th2 response, with production of interleukins such as IL-4 and IL-13 that permit tumor growth. TAMinfiltrating tumors correlate with worse clinical outcome and are closely associated with the alternatively activated (M2) phenotype. These TAMs have been demonstrated to produce EGF, IL-6, and IL-10 and have been associated with angiogenesis, local tumor progression, and metastasis. ${ }^{55}$ Through these immune/inflammatory cells and mediators, HNSCC induces an immunosuppressed state via multiple potent mechanisms, which is a barrier to effective cancer immunotherapy. ${ }^{56}$

\section{IMMUNE EVASION OF HPV-ASSOCIATED HNSCC}

HPV infection and immune evasion in HPV-associated cancers is a clinically relevant model for immunotherapy. A critical component in avoiding adaptive and innate immune response is HPV's interference with IFNs and other signaling pathways. IFNs link the innate immunity response to the adaptive immunity response by activating immature DCs and $\mathrm{CD} 8^{+} \mathrm{T}$ cells and producing virus-specific antibodies. ${ }^{57,58}$ Interferon-alfa (IFN- $\alpha$ ) and interferon-beta (IFN- $\beta$ ) have immunostimulatory properties, are produced by virally infected cells and execute their antiviral effects through inhibition of mRNA, NKcell stimulation, and inhibition of viral protein expression. ${ }^{57} \mathrm{IFN}-\gamma$ activates leukocyte migration, antigen presentation, and inflamma- tion and is primarily produced by effector lymphocytes. Therefore, antiviral immune response critically depends on inflammatory signaling, as evidenced by the frequent inactivating mutations in the TNF receptor-associated factor 3, or the TRAF3 gene, found in The Cancer Genome Atlas. ${ }^{20}$ Danger signals, such as TLRs, present on inflammatory cells can also help to detect so-called pathogen-associated molecular patterns ${ }^{59}$ to stimulate these IFN's. Furthermore, HPV interacts with antigen presentation to reduce adaptive immune response and suppresses STAT1 signaling inhibition by IFN pathways, causing downregulation of HLA class I APM. ${ }^{59,60}$ Genetic host polymorphisms, ${ }^{61}$ and even mutations, such as the recently identified $10 \%$ to $12 \%$ frequency of genomic alterations in HLA/TAP/ $\beta 2 \mathrm{M}$ antigen processing/presentation pathways, ${ }^{20}$ may present an ultimate barrier to successful immunotherapy in these patients.

During normal immune responses, the presence of checkpoint receptors, such as PD-1 or CTLA-4, limits an overrobust immune response to protect from autoimmune reactivity. ${ }^{62,63}$ In patients with HNSCC, elevated PD-1 expression has been observed on $\mathrm{CD} 8^{+} \mathrm{HPV}$ positive tumor-infiltrating lymphocytes ${ }^{64}$ but, unexpectedly, patients with high numbers of PD-1-expressing T-cell infiltration have shown a better 5-year overall survival rate (93.9\%) compared with those patients with low PD-1-expressing T-cell infiltration $(63.6 \%){ }^{64}$ This potentially conflicting observation may reflect a quantitatively greater overall antitumor immune response, because proinflammatory conditions can stimulate PD-L1 expression. Interestingly, PD-L1 expression of tumor tissue was not correlated to clinical outcome. ${ }^{64}$ As a result, the quality and quantity of tumor-infiltrating lymphocytes (TILs) determines the antitumor response. This is confirmed by recent studies correlating the number of TILs in patients with HPV-positive oropharyngeal squamous cell cancer with disease prognosis. ${ }^{65,66}$ Badoual et $\mathrm{al}^{64}$ also observed a higher number of tumor infiltrations with Tregs in HPV-positive oropharyngeal squamous cell cancer. So far, the reasons for the better prognosis of HPV-positive patients despite all of the mentioned HPV-and non-HPV-associated immune evasion mechanisms remain unclear.

\section{HPV-Specific Cancer Immunoprevention Strategies}

The most successful HNSCC-targeted immunotherapy will likely be HPV-targeted immunoprevention vaccines. The aim of the preventive vaccines is to inhibit viral infection and thus hinder cancer formation. The immunization targets the L1 capsid proteins and is realized by using virus-like particles. These particles provoke a humoral antibody response and, interestingly, generate a significantly stronger humoral response than natural infection. ${ }^{67}$ Several large randomized, double-blinded, placebo-controlled phase III trials demonstrated high efficacy (recombinant HPV vaccine [types $6,11,16,18$ ] , $96.8 \%$ to $100 \%$; recombinant HPV bivalent vaccine [types 16 and 18], 90.9\% to $100 \%$ ) in prevention of benign and malignant HPV-associated cervical lesions. ${ }^{68}$ The effects of the vaccination on oropharyngeal lesion has not yet been fully evaluated but is expected to have promising results, considering the achieved antiviral results so far and the rising prevalence of HPVpositive oropharynx carcinoma. ${ }^{60,69}$ The GlaxoSmithKline vaccine delivered in a randomized, placebo-controlled Costa Rican cohort demonstrated significantly reduced (nearly eliminated) oral HPV infection in the vaccine group, ${ }^{70}$ suggesting a potential benefit for reducing future oropharyngeal squamous cell cancer cases. Because these prevention vaccines induce L1 capsid-specific Abs 2 to 
3 log-folds higher than natural infection, they prevent viral entry and initial infection. However, because established HPV infection leads to viral DNA integration and expression of intracellular E6 and E7 oncogenes and loss of L1 expression, these prevention vaccines are ineffective for previous infections and are not therapeutic tools for established HPV-associated cancers.

\section{IMMUNOTHERAPIES IN ESTABLISHED HPV-RELATED HNSCC}

Several vaccination therapies under development in HNSCC have yielded modest results to date. Peptide vaccines consist of synthesized peptides that have been designed to correspond to an epitope on a tumor antigen that binds well to the cleft of an HLA molecule. They are similar to DNA vaccines in that they are safe and inexpensive with low immunogenicity but have the drawback of being restricted to the HLA subclass (allele) for which they were designed according to specific HLA allele binding properties. Clinical trials are under way with a melanoma antigen A3/HPV-16 peptide (NCT00257738) and a latent membrane protein 2 peptide for Epstein-Barr virus-related nasopharyngeal carcinoma (NCT00078494).

Bacterial/viral vaccines can deliver tumor antigen as well as function as an immune adjuvant because of immune system responses to a perceived infection. Several such vaccines are currently under development: HPV-16 E7 Listeria vaccine, ${ }^{71}$ vaccinia-based E6/E7 vaccine, ${ }^{72}$ and a vaccinia-based E2-expressing vaccine. ${ }^{73}$ Other vectors include bacterial-based HPV vaccines targeting E7, which showed preclinical effects and are in clinical investigation. ${ }^{71}$ The viral vector TG4001 (encoding HPV E6/E7 and IL-2) was also used in a phase II trial of malignant lesions in combination with chemoradiation. ${ }^{74}$

Another major avenue of immunotherapy for $\mathrm{HNC}$ is adoptive T-cell transfer. In this approach, T cells are removed from a patient, genetically modified or treated with agents to enhance their activity, and then reintroduced into the patient with the goal of improving the immune system's anticancer response. Several trials of adoptive T-cell transfer techniques are currently under way for patients with $\mathrm{HNC}$, for example, a phase II trial of TILs for HPV-associated cancers, including HNSCCs, at the US National Cancer Institute (NCT01585428).

DCs are the most potent activators of antigen-specific T cells, but DC vaccines are produced as a cellular product ex vivo, isolated from each patient and loaded with tumor antigen ex vivo. This loading can be in the form of peptides, proteins, DNA transfection, tumor cell lysates, apoptotic tumors, necrotic tumors, or cell fusion. After maturation and activation with various cytokine cocktails, these DCs are then introduced into the patients, usually into the tumor or into lymph nodes. Several DC-based vaccines are currently being developed for HNSCC, including intratumoral injection of DC (NCT00492947), multivalent p53 DC vaccine, ${ }^{75}$ and lysyl oxidase-like 4 transfected DC. ${ }^{76}$

\section{MOAB-BASED IMMUNOTHERAPY OF HNSCC}

Today the most widely used form of cancer immunotherapy is moAb therapy, ${ }^{77}$ including tumor antigen (TA) -targeted moAbs, cytokinetargeted moAbs, tumor necrosis factor receptor family costimulatory targeted moAbs and immune checkpoint-targeted moAbs. Currently available moAbs that are being investigated in HNSCC are listed in Table 2. The most extensively studied (and approved by the US Food and Drug Administration for HNSCC) of these drugs is cetuximab, a mouse-human chimeric immunoglobulin G1 (IgG1) anti-EGFR moAb. ${ }^{78}$ EGFR is an attractive target in HNSCC because it is overexpressed in $80 \%$ to $90 \%$ of HNSCCs and leads to tumor cell proliferation and invasion, angiogenesis, tumor survival, and, consequently, poor survival and prognosis. ${ }^{79}$

\begin{tabular}{|c|c|c|c|}
\hline Drug (company) & Target & $\lg$ Class & HNSCC Development Stage \\
\hline \multicolumn{4}{|l|}{ Tumor antigen-targeted moAbs } \\
\hline Cetuximab (Bristol-Myers Squibb, Eli Lilly) & EGFR antagonist & $\lg \mathrm{G} 1$ & Phase III and IV \\
\hline Panitumumab (Amgen) & EGFR antagonist & $\lg \mathrm{L} 2$ & Phase II and III \\
\hline AV-203 (Aveo) & HER3 antagonist & $\operatorname{lgG} 1$ & Phase I (monotherapy; cetuximab combination) \\
\hline Cixutumumab (Eli Lilly) & IGFR antagonist & $\lg \mathrm{G} 1$ & Phase 0-II (neoadjuvant monotherapy; cetuximab combination) \\
\hline \multicolumn{4}{|l|}{ Cytokine-targeted moAbs } \\
\hline Bevacizumab (Genentech) & VEGF-neutralizing Abs & $\lg \mathrm{G} 1$ & Phase III (platinum chemotherapy \pm ) \\
\hline Ficlatuzumab (Aveo) & HGF-neutralizing Abs & $\lg \mathrm{g} 1$ & Phase I (cetuximab combination; cisplatin-radiation combination) \\
\hline \multicolumn{4}{|l|}{ TNF receptor-targeted moAbs } \\
\hline MEDI0562 (Astra-Zeneca/Medimmune) & OX40 agonist & $\lg \mathrm{g} 2$ & Phase IB \\
\hline Urelumab (Bristol-Myers Squibb) & CD137 agonist & $\operatorname{lgG} 4$ & Phase I \\
\hline PF-05082566 (Pfizer) & CD137 agonist & $\lg G 2$ & Phase 1 \\
\hline \multicolumn{4}{|l|}{ Immune checkpoint-targeted moAbs } \\
\hline Ipilimumab (Bristol-Myers Squibb) & CTLA4 & $\lg \mathrm{G} 1$ & Phase I (cetuximab-radiation combination) \\
\hline Tremelimumab (AZ/Medimmune) & CTLA4 & $\lg G 2$ & Phase I \\
\hline Darvalumab (MEDI4736, & & & \\
\hline AZ/Medimmune) & PD-L1 & $\operatorname{lgG} 1$ & Phase II \\
\hline Pembrolizumab (MK-3475, Merck) & PD-1 & $\lg 44$ & Phase I \\
\hline Nivolumab (Bristol-Myers Squibb/ONO) & PD-1 & $\lg G 4$ & Phase III \\
\hline
\end{tabular}


Anti-EGFR moAbs mediate antigen-specific immune responses to targeted tumors through two major mechanisms: direct killing via lytic immune cell (NK cells or monocytes) and complement fixation, or opsonization of tumor for phagocytosis and subsequent antigen processing. The latter induces TA-specific cytotoxic T lymphocytes (CTLs) to recognize and lyse tumor cells. One of the most direct methods that antibodies can cause tumor lysis is via antibodydependent cellular cytotoxicity mediated by NK cells and probably monocytes and neutrophils. The extent of antibody-dependent cellular cytotoxicity is heavily influenced by genetic polymorphisms in Fc $\gamma$ RIIIa (CD16); ${ }^{80}$ however, confirmatory clinical data in HNSCC patients are lacking. In addition to direct activation of NK-cell lysis of tumor cells, TA-specific moAbs can elicit $\mathrm{CD} 8^{+} \mathrm{T}$-cell responses to tumor-derived antigens through interaction with Fc $\gamma$ Rs on antigenpresenting cells. This antigen-specific T-cell activation was noted in $78 \%$ of patients treated with trastuzumab for breast cancer, and this activation seemed to correlate positively with clinical response. ${ }^{81}$ Specific T-cell activation has been demonstrated in patients with HNSCC treated with cetuximab, ${ }^{82,83}$ alone or in combination with cisplatin chemotherapy. In addition to extensive clinical and correlative immune response data on use of cetuximab, MEHD7945A, an anti-HER3/EGFR human moAb targeting human epidermal growth factor receptor 3 and EGFR is currently being tested in phase I and II clinical trials for HNSCC (NCT01577173, NCT01911598).

\section{IMMUNE CHECKPOINTS AND INHIBITORS}

T-cell activation occurs through a combination of T-cell-receptor engagement and costimulatory molecules. The duration and extent of immune responses - for example, to infections — is regulated by "immune checkpoints," or inhibitory pathways that prevent excessive inflammatory responses as well as development of autoimmunity. Immune checkpoints have also been shown to play an important role in the tumor microenvironment and can be manipulated as a mechanism of tumor immune evasion. ${ }^{84}$ The immune checkpoint pathways are mediated by ligand and receptor interactions, for example, CTLA-4 and its ligands CD80 and CD84 and PD-1 and its ligands PD-L1 and PD-L2. Blocking anti-CTLA-4 moAb therapy results in rejection of murine cancers. ${ }^{85} \mathrm{~A}$ moAb against CTLA-4, ipilimumab, was the first drug in this class to demonstrate clinical benefit and was approved by the US Food and Drug Administration for patients with metastatic melanoma. ${ }^{86}$ Tremelimumab is also available for CLTA-4 targeting. More recently, anti-PD-1 or PD-L1 Abs have demonstrated clinical efficacy, alone ${ }^{87-89}$ or in combination with ipilimumab. ${ }^{90}$

\section{PD-L1 PATHWAY TARGETING IN HNSCC}

PD-1 (CD279), a 55-kDa type I transmembrane protein, is a member of the CD28 family of T-cell costimulatory receptors, which also includes CTLA 4, ICOS, and BTLA. PD-1 contains an intracellular membrane proximal immunoreceptor tyrosine inhibitory motif and a membrane distal immunoreceptor tyrosine-based switch motif. Two ligands specific for PD-1 have been identified: PD-L1 (B7-H1/CD274) and PD-L2 (B7-DC/CD273). PD-L1 and PD-L2 have been shown to downregulate $\mathrm{T}$-cell activation on binding to $\mathrm{PD}-1$ in both murine and human systems. PD-1 delivers a negative signal, suppressing type 1 -based antitumor immunity ${ }^{91}$ by the recruitment of the tyrosine phosphatase SHP-2 to the phosphorylated tyrosine residue in the immunoreceptor tyrosine-based switch motif in its cytoplasmic region, skewing the immune response away from a beneficial type 1 response. PD-1 is primarily expressed on activated T cells, B cells, and myeloid cells. PD-1 blockade has the potential to activate antiself $\mathrm{T}$-cell responses, but these responses are variable and dependent on various host genetic factors.

Tumor immune evasion can occur by high tumor expression of PD-L1 and/or tumor immune infiltration by PD-1-positive T lymphocytes. Preliminary analyses indicate that PD-L1 is expressed in $50 \%$ to $60 \%$ of HNSCCs and that tumor infiltration by PD-1-positive Tregs may be more common for HPV-positive than HPV-negative HNSCCs. Strome et al reported membrane and or intracytoplasmic PD-L1 expression in 66\% (16 of 24) of HNSCC. Badoual et $\mathrm{al}^{64}$ reported tumor infiltration by $\mathrm{PD}$-1-positive CD8 ${ }^{+}$ lymphocytes and $\mathrm{PD}-1$-positive $\mathrm{CD} 4^{+}$lymphocytes was more common among HPV-positive than HPV-negative HNSCCs. In 33 (55\%) of 64 HNSCCs, high levels of PD-L1 expression were observed, but there was no association between PD-L1 expression and tumor HPV status. Jie et $\mathrm{al}^{92}$ observed higher expression of immune checkpoint receptors (CTLA-4 and PD-1) in intratumoral Treg cells than in matched peripheral blood samples from 27 patients with HNSCC. These data strongly support a role for PD-1 inhibition in the therapy of HNSCC.

\section{CHECKPOINT RECEPTOR TARGETED MOABS IN COMBINATION} WITH CETUXIMAB

Cetuximab therapy alters expression of checkpoint receptors on circulating and intratumoral TILs. Specifically, the frequency of Treg suppressor cells that express CTLA- 4 and PD- 1 are enriched in the tumor microenvironment. ${ }^{92}$ Furthermore, cetuximab therapy increased the frequency of $\mathrm{CD} 4{ }^{+} \mathrm{CD} 25^{\text {hi }} \mathrm{CD} 39^{+} \mathrm{FOXP} 3{ }^{+}$Treg $(P=.01)$, indicating that this treatment expands Treg in patients with HNSCC. CTLA $-4^{+} / \mathrm{CD} 39^{+}$cells were significantly increased among the majority of $\mathrm{CD} 4^{+} \mathrm{FOXP} 3^{+}$Treg from patients before and after cetuximab treatment, indicating that CTLA-4 targeting may provide enhanced benefit in patients treated with cetuximab. ${ }^{92}$ Recent data in non-small-cell lung carcinoma indicate that the EGFR pathway may contribute to regulation of PD-L1 expression, ${ }^{93}$ a finding corroborated in HNSCC (Concha-Benavente and Ferris, unpublished data).

These emerging data support the incorporation of checkpoint inhibitory moAbs into conventional HNSCC therapy, either to deplete Treg or to disrupt the PD-1:PD-L1 suppressive signal transmitted to $\mathrm{CD}^{+}$effector $\mathrm{T}$ lymphocytes. These suppressed NK cells and T cells express the negative regulatory PD-1 receptor, at higher levels and generating greater inhibitory signals in tumorinfiltrating lymphocytes, providing a strong rationale for combining cetuximab with anti-PD-1 moAb therapy in a curative setting in which traditional cytotoxic chemotherapy may impart deleterious effect(s) on the generation and proliferation of beneficial antitumor lymphocyte responses. 


\section{COSTIMULATORY AGONISTIC STRATEGIES}

In addition to blocking negative regulatory receptors on lymphocytes, another strategy has emerged-to enhance and trigger positive, costimulatory signals using agonistic Abs and small molecules. So far, the investigation of tumor necrosis factor receptor targeting moAbs for HNSCC in clinical trials is in phase I. Because of the important costimulatory pathways for immune cell activation, substances like CP870,893, an IgG2 CD40 agonist, OX40 moAb, an IgG2 OX40 agonist, and urelumab, an IgG4 CD137 agonist, are being investigated with cetuximab or with nivolumab in clinical trials ${ }^{94}$ that are currently enrolling patients with HNSCC. TLR agonists induce the maturation and cross-priming of DCs and have been shown to induce NK celldependent lysis of tumor cells in combination with moAbs such as anti-EGFR cetuximab. ${ }^{95}$

\section{INTEGRATION OF IMMUNOTHERAPY INTO CLINICAL PRACTICE}

The integration of this new modality into standard clinical practice must adapt to different stages and disease status of HNSCC patients, depending on the clinical needs for each population of individuals. Indeed, monoclonal Abs targeting PD-1 and CTLA-4 (and others) are being investigated in several clinical trials now that US Food and Drug Administration approval exists for these agents in melanoma and lung cancer. Indeed, in November 2014, the National Cancer Institute funded the Clinical Trials Planning Meeting to facilitate rational design of combinations of immunotherapies for phase II and III randomized trials in HNSCC.

\section{PREVIOUSLY UNTREATED, LOCALLY ADVANCED HNSCC}

For HPV-positive, previously untreated, locally advanced (PULA) HNSCC, the clinical need is more targeted, less toxic therapy and to determine the sequencing and optimal chemoradiation regimens that do not inhibit immunotherapeutic efficacy. Specifically, trials need to harness this novel systemic therapy to make an impact on the burden of uncommon, though lethal, distant metastatic disease for high risk HPV-positive patients with advanced disease (T4, N2c/N3, > 10 pack-year smokers). Trials planned or in development include eliminating systemic cytotoxic chemotherapy by combining intensity-modulated radiation therapy (IMRT) with cetuximab and anti-CTLA-4 moAbs (ipilimumab, NCT01935921), in which the overlap of moAb exposure begins at week 5 of cetuximab/radiotherapy (RT). In the first six patients accrued, two dose-limiting toxicities were experienced (dermatologic toxicity, leading to dose reduction from 3 to 1 $\mathrm{mg} / \mathrm{kg}$ of ipilimumab, R.L. Ferris and J.E. Bauman, unpublished results). In addition, intermediate risk HPV-positive and high risk HPV-negative patients will be treated with concurrent, weekly cisplatin chemoradiation therapy with anti-PD-1 moAbs, a natural add-on strategy that is in development by the RTOG for prospective evaluation in the near future.

For HPV-negative PULA HNSCC patients, disease-free survival has not improved beyond the historical $50 \%$ rate for decades, despite concomitant treatment intensification. Thus, the clinical impact of immunotherapy would be to improve disease-free sur- vival, given that intensification using conventional modalities has been unacceptably toxic. Intensifying therapy to enhance survival using anti-PD-1 moAbs plus conformal radiation therapy will be tested for HPV+ disease. Neoadjuvant approaches will also take advantage of tumor accessibility for serial biomarker testing. Trials sequencing anti-PD-1 before, during, or after RT are being developed to evaluate complex effects on immunity stimulated during these combinatorial trials.

Thus, for HPV-positive and HPV-negative locally advanced HNSCCs, checkpoint inhibitors (anti-PD-1 or anti-CTLA-4) combined with cisplatin/IMRT are being investigated for adjuvant, postoperative PULA HPV-negative disease and for upfront treatment of high risk advanced disease-stage HPV \pm PULA HNSCC, in combination with cisplatin- or cetuximab-IMRT (Table 3 ).

\section{RECURRENT/METASTATIC HNSCC}

In recurrent/metastatic HNSCC, the usual disease setting in which novel therapeutics are initially tested, a proliferation of immunotherapeutic Abs and combinations has occurred (Table 2). In a phase I clinical trial investigating the anti-PD-1 monoclonal antibody pembrolizumab (MK-3475) for targeting advanced/recurrent HNSCC, responses were observed in patients regardless of HPV status, including those without detectable PD-L1 expression. ${ }^{96}$ Of 60 patients, 23 were HPV-positive and 37 were HPVnegative; 9 had no previous systemic treatment, 10 had one, 16 had two, 13 had three, and 7 had four or more (with the number for 5 patients unknown). Of the patients treated with anti-PD-1 moAbs, $78.3 \%$ experienced at least one adverse event, and $46.7 \%$ reported a drug-related adverse event. The most common adverse events reported were pruritis $(6 ; 10 \%)$, fatigue $(4 ; 7 \%)$, rash $(4 ; 7 \%)$, and diarrhea $(3 ; 5 \%)$. Response rates (partial response/complete response) were approximately $20 \%$ and were similar in both HPVpositive and HPV-negative HNSCC patients. Recurrent and metastatic HNSCC has seen modest survival improvements through addition of cetuximab to doublet chemotherapy of platinum/fluourouracil. ${ }^{97}$ Whether anti-PD-1 therapy can further enhance these outcomes is a logical line of investigation (Table 3 ).

Adding immunotherapeutics to standard cetuximab-containing regimens is a natural line of investigation. VTX-2337 is a TLR8 agonist currently being tested in a randomized phase II clinical trial in firstline recurrent/metastatic HNSCC in combination with platinum/ fluorouracil/cetuximab (NCT01836029, $\mathrm{n}=175$ patients). For cisplatin-refractory recurrent/metastatic HNSCC, two blocking antiPD-1 Abs, nivolumab (NCT02105636; $\mathrm{n}=340$ patients) and pembrolizumab (NCT02358031; $\mathrm{n}=750$ patients), are being investigated as a single agent in randomized phase III trials for platinum-refractory HNSCC. Anti PD-L1 (MEDI4736) has generated additional promising data ( $\sim 14 \%$ response rate scored using RECIST criteria, with $24 \%$ response rate in PD-L1-positive patients) in a phase I trial, ${ }^{97 a}$ warranting the design of a randomized phase III trial of MEDI4736 alone or in combination with anti-CTLA-4 (tremelimumab), as compared with standard-of-care agents. Stratification by PD-L1 expression status is planned, and follow-ups on phase II trials are currently accruing. Another new phase III trial in the first-line recurrent/metastatic setting (NCT02358031) will compare anti-PD-1 (pembrolizumab) alone or 


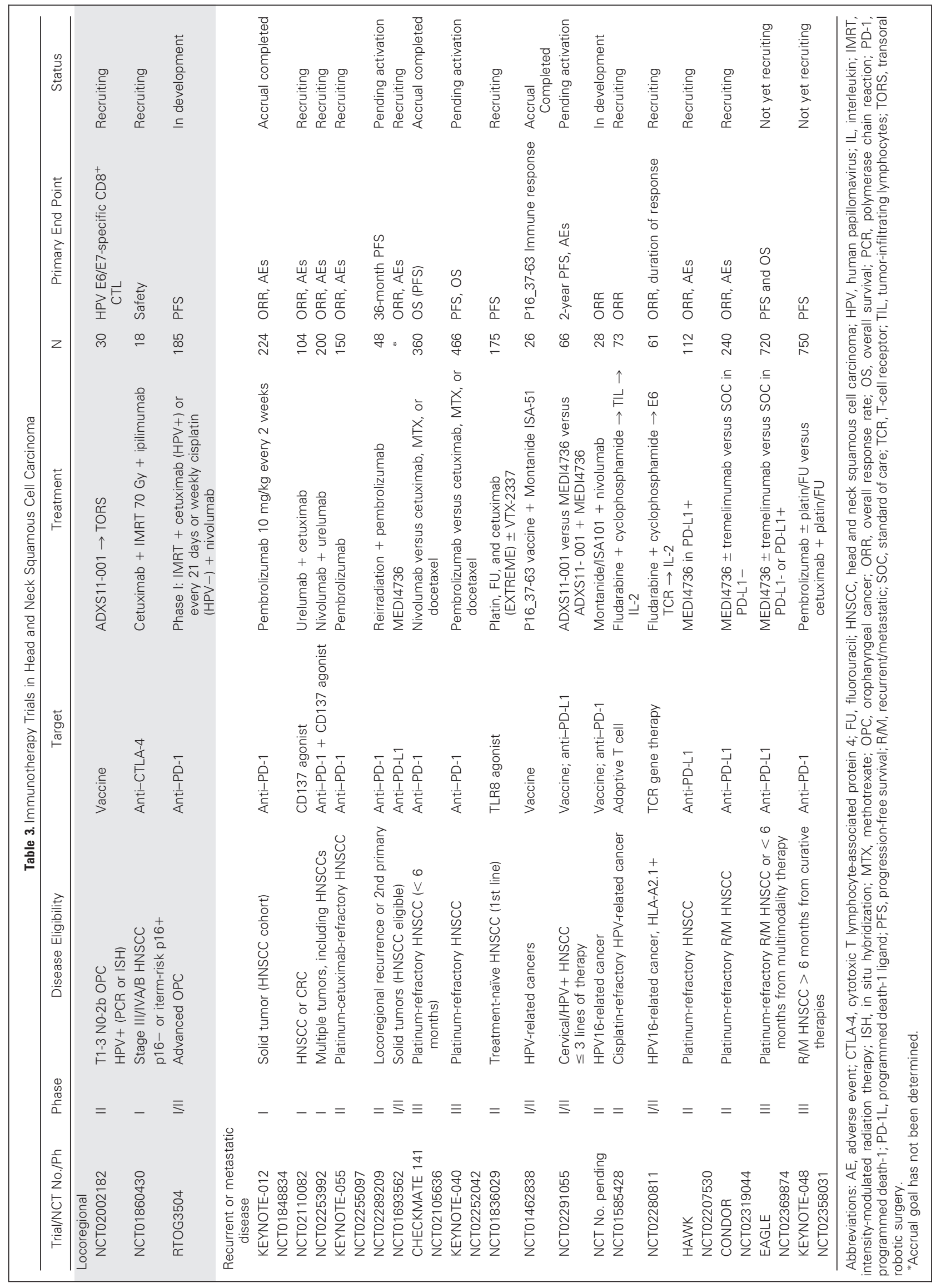


in combination with platinum/fluorouracil versus cetuximab/platinum/fluorouracil (EXTREME regimen).

A different group of receptors with a modulating effect on immune cells includes other checkpoint receptors such as LAG-3 or the killer-cell immunoglobulin-like receptors (KIRs). They interact with MHC I molecules and regulate immune response. Most of the receptors have a suppressing effect on cytotoxicity, particularly turning off NK cells when HLA is present on tumor cells. Anti-KIR Abs thus might remove the major inhibitory signal on NK cells. Ongoing trials are investigating an anti-KIR moAb in combination with the antiCTLA-4 moAb ipilimumab (NCT01750580) or anti PD-1 moAb nivolumab (NCT01714739). Anti-PD-1 moAbs are also being tested in various novel combinations in the phase I setting, such as nivolumab plus agonistic anti-CD137 moAbs (urelumab, NCT02253992), nivolumab plus anti-LAG-3 (NCT01968109), and cetuximab plus urelumab. A more complete listing of trials open or in late stages of development is provided in Table 3.

\section{CHECKPOINT INHIBITORS AND RADIOTHERAPY}

In addition to direct cytotoxic effects, RT may induce an immune effect important for tumor cell death. ${ }^{98}$ Preclinical data support synergy between checkpoint inhibitors and RT. Mouse models of poorly immunogenic tumors have demonstrated that concomitant administration of anti-CTLA- 4 antibodies and RT results in antitumor T-cell responses both in the radiation field and outside of it (an abscopal effect). ${ }^{98,99}$ PD-1 blockade after completion of RT also has been shown to induce rejection of persistent tumors in mouse models. Combination PD-1 blockade and anti-CD137 stimulation increased response to RT in a mouse model of triplenegative breast cancer, ${ }^{100}$ and PD-L1 blockade concomitant with RT improved survival in comparison with either therapy alone in mouse models of glioma. ${ }^{101}$ In humans, case reports support the existence of a clinically significant abscopal effect for patients with melanoma who had received ipilimumab before RT. ${ }^{102,103}$ These data support a hypothesis that checkpoint inhibitors administered before or concomitant with RT can induce clinically significant antitumor immune responses induced by vaccination to tumorspecific antigens exposed during radiation-induced cell death. ${ }^{104}$ Such a phenomenon may be particularly relevant to viral-induced tumors, such as HPV-positive HNSCC, and to highly genetically unstable tumors, such as HPV-negative HNSCCs.

In conclusion, cancer immunology is a rapidly evolving field, and only recently have we begun to understand the complex interaction between cancer and the host immune system. Tumor cells demonstrate several methods to exploit the immune system to help promote angiogenesis, derive prosurvival and proliferative signals, and induce metastasis and tumor progression. At the same time, cancers are able to cloak themselves from the immune system by self-modification and by immunosuppression of the host. Recent results from clinical trials show evidence for effective anticancer immunotherapies. Because of the manifold tumor evasion strategies and hence different response rates for treatments, combinational therapies are crucial to develop for cancer treatment. These insights and better understanding of the workings of the immune system have allowed the recent explosion of promising immunotherapeutic agents that are currently in clinical use as well as others under development.

\section{AUTHOR'S DISCLOSURES OF POTENTIAL CONFLICTS} OF INTEREST

Disclosures provided by the authors are available with this article at www.jco.org.

\section{REFERENCES}

1. Leibowitz MS, Andrade Filho PA, Ferrone S, et al: Deficiency of activated STAT1 in head and neck cancer cells mediates TAP1-dependent escape from cytotoxic $T$ lymphocytes. Cancer Immunol Immunother 60:525-535, 2011

2. Leibowitz MS, Srivastava RM, Andrade Filho PA, et al: SHP2 is overexpressed and inhibits pSTAT1-mediated APM component expression, T-cell attracting chemokine secretion, and CTL recognition in head and neck cancer cells. Clin Cancer Res 19:798-808, 2013

3. Kuss I, Hathaway B, Ferris RL, et al: Decreased absolute counts of $T$ lymphocyte subsets and their relation to disease in squamous cell carcinoma of the head and neck. Clin Cancer Res 10: 3755-3762, 2004

4. Bauernhofer T, Kuss I, Henderson B, et al: Preferential apoptosis of CD56dim natural killer cell subset in patients with cancer. Eur $\mathrm{J}$ Immunol 33:119-124, 2003

5. Dasgupta S, Bhattacharya-Chatterjee $M$, O'Malley BW Jr, et al: 2005. Inhibition of NK cell activity through TGF-beta 1 by down-regulation of NKG2D in a murine model of head and neck cancer. J Immunol 175:5541-5550, 2005

6. Lopez-Albaitero A, Nayak JV, Ogino T, et al: Role of antigen-processing machinery in the in vitro resistance of squamous cell carcinoma of the head and neck cells to recognition by CTL. J Immunol 176:3402-3409, 2006

7. Ferris $R$, Whiteside $T L$, Ferrone S: Clinical significance of downregulated antigen processing machinery in head and neck cancer. Clin Cancer Res 12:3890, 2006

8. Whiteside TL: Immune cells in the tumor microenvironment: Mechanisms responsible for functional and signaling defects. Adv Exp Med Biol 451:167-171, 1998

9. Ferris RL: Progress in head and neck cancer immunotherapy: Can tolerance and immune suppression be reversed? ORL J Otorhinolaryngol Relat Spec 66:332-340, 2004

10. Galon J, Costes A, Sanchez-Cabo F, et al: Type, density, and location of immune cells within human colorectal tumors predict clinical outcome. Science 313:1960-1964, 2006

11. Kammertoens $T$, Schüler $T$, Blankenstein $T$ : Immunotherapy: Target the stroma to hit the tumor. Trends Mol Med 11:225-231, 2005

12. Herberman RB, Holden HT: Natural cellmediated immunity. Adv Cancer Res 27:305-377, 1978

13. Dunn GP, Bruce AT, Ikeda $H$, et al: Cancer immunoediting: From immunosurveillance to tumor escape. Nat Immunol 3:991-998, 2002

14. Russell JH, Ley TJ: Lymphocyte-mediated cytotoxicity. Annu Rev Immunol 20:323-370, 2002
15. Gillison ML: Oropharyngeal cancer: A potential consequence of concomitant HPV and HIV infection. Curr Opin Oncol 21:439-444, 2009

16. D'Souza G, Carey TE, William WN Jr, et al: Epidemiology of head and neck squamous cell cancer among HIV-infected patients. J Acquir Immune Defic Syndr 65:603-610, 2014

17. Jain A, Reyes J, Kashyap R, et al: What have we learned about primary liver transplantation under tacrolimus immunosuppression? Long-term follow-up of the first 1000 patients. Ann Surg 230:441-448, 1999; discussion 448-449

18. Birkeland SA, Storm HH, Lamm LU, et al: Cancer risk after renal transplantation in the Nordic countries, 1964-1986. Int J Cancer 60:183-189, 1995

19. Mittal D, Gubin MM, Schreiber RD, et al: New insights into cancer immunoediting and its three component phases: Elimination, equilibrium and escape. Curr Opin Immunol 27:16-25, 2014

20. The Cancer Genome Atlas Network: Comprehensive genomic characterization of head and neck squamous cell carcinomas. Nature 517:576582, 2015

21. Grandis JR, Falkner DM, Melhem MF, et al: Human leukocyte antigen class I allelic and haplotype loss in squamous cell carcinoma of the head and neck: Clinical and immunogenetic consequences. Clin Cancer Res 6:2794-2802, 2000

22. Mizukami $Y$, Kono $K$, Maruyama $T$, et al: Downregulation of HLA class 1 molecules in the 
tumour is associated with a poor prognosis in patients with oesophageal squamous cell carcinoma. Br J Cancer 99:1462-1467, 2008

23. Ogino $T$, Shigyo $H$, Ishii $H$, et al: HLA class I antigen down-regulation in primary laryngeal squamous cell carcinoma lesions as a poor prognostic marker. Cancer Res 66:9281-9289, 2006

24. Ferris $R L$, Whiteside $T L$, Ferrone $S$ : Immune escape associated with functional defects in antigen-processing machinery in head and neck cancer. Clin Cancer Res 12:3890-3895, 2006

25. Zandberg DP, Strome SE: The role of the PD-L1:PD-1 pathway in squamous cell carcinoma of the head and neck. Oral Oncol 50:627-632, 2014

26. Zou W, Chen L: Inhibitory B7-family molecules in the tumour microenvironment. Nat Rev Immunol 8:467-477, 2008

27. Strauss L, Bergmann C, Gooding W, et al: The frequency and suppressor function of CD4+CD25 highFoxp3 + T cells in the circulation of patients with squamous cell carcinoma of the head and neck. Clin Cancer Res 13:6301-6311, 2007

28. Sega El, Leveson-Gower DB, Florek M, et al: Role of lymphocyte activation gene-3 (Lag-3) in conventional and regulatory $T$ cell function in allogeneic transplantation. PLoS One 9:e86551, 2014

29. Ferris RL, Lu B, Kane LP: Too much of a good thing? Tim-3 and TCR signaling in T cell exhaustion. $\mathrm{J}$ Immunol 193:1525-1530, 2014

30. Yang ZZ, Grote DM, Ziesmer SC, et al: IL-12 upregulates TIM-3 expression and induces T cell exhaustion in patients with follicular B cell non-Hodgkin lymphoma. J Clin Invest 122:1271-1282, 2012

31. Jebreel A, Mistry $D$, Loke $D$, et al: Investigation of interleukin 10, 12 and 18 levels in patients with head and neck cancer. J Laryngol Otol 121:246-252, 2007

32. Moutsopoulos NM, Wen J, Wahl SM: TGFbeta and tumors: An ill-fated alliance. Curr Opin Immunol 20:234-240, 2008

33. Cheng F, Wang HW, Cuenca $A$, et al: $A$ critical role for Stat3 signaling in immune tolerance. Immunity 19:425-436, 2003

34. Duffy SA, Taylor JM, Terrell JE, et al: Interleukin-6 predicts recurrence and survival among head and neck cancer patients. Cancer 113:750-757, 2008

35. Murray PJ: STAT3-mediated anti-inflammatory signalling. Biochem Soc Trans 34:1028-1031, 2006

36. Sun $Y$, Chin YE, Weisiger $E$, et al: Cutting edge: Negative regulation of dendritic cells through acetylation of the nonhistone protein STAT-3. J Immunol 182:5899-5903, 2009

37. Kortylewski $M$, Xin $H$, Kujawski $M$, et al: Regulation of the IL-23 and IL-12 balance by Stat3 signaling in the tumor microenvironment. Cancer Cell 15:114-123, 2009

38. Pallandre JR, Brillard $E$, Crehange $G$, et al: Role of STAT3 in CD4+CD25+FOXP3+ regulatory lymphocyte generation: Implications in graft-versushost disease and antitumor immunity. J Immunol 179:7593-7604, 2007

39. Snyderman $\mathrm{CH}$, Milanovich $\mathrm{M}$, Wagner RL, et al: Prognostic significance of prostaglandin E2 production in fresh tissues of head and neck cancer patients. Head Neck 17:108-113, 1995

40. Camacho $M$, Leon $X$, Fernandez-Figueras MT, et al: Prostaglandin E(2) pathway in head and neck squamous cell carcinoma. Head Neck 30:11751181, 2008

41. Harris SG, Padilla J, Koumas L, et al: Prostaglandins as modulators of immunity. Trends Immunol 23:144-150, 2002
42. Seiwert TY, Cohen EE: Targeting angiogenesis in head and neck cancer. Semin Oncol 35:274285, 2008

43. Johnson BF, Clay TM, Hobeika AC, et al: Vascular endothelial growth factor and immunosuppression in cancer: Current knowledge and potential for new therapy. Expert Opin Biol Ther 7:449-460, 2007

44. Pak AS, Wright MA, Matthews JP, et al: Mechanisms of immune suppression in patients with head and neck cancer: Presence of CD34(+) cells which suppress immune functions within cancers that secrete granulocyte-macrophage colonystimulating factor. Clin Cancer Res 1:95-103, 1995

45. Ostrand-Rosenberg S, Sinha P: Myeloidderived suppressor cells: Linking inflammation and cancer. J Immunol 182:4499-4506, 2009

46. Grizzle WE, Xu X, Zhang $S$, et al: Age-related increase of tumor susceptibility is associated with myeloid-derived suppressor cell mediated suppression of $\mathrm{T}$ cell cytotoxicity in recombinant inbred BXD12 mice. Mech Ageing Dev 128:672-680, 2007

47. Sakaguchi $S$, Sakaguchi $N$, Asano $M$, et al: Immunologic self-tolerance maintained by activated T cells expressing IL-2 receptor alpha-chains (CD25): Breakdown of a single mechanism of self-tolerance causes various autoimmune diseases. J Immunol 155:1151-1164, 1995

48. Cosmi L, Liotta F, Lazzeri $E$, et al: Human CD8+CD25+ thymocytes share phenotypic and functional features with $\mathrm{CD} 4+\mathrm{CD} 25+$ regulatory thymocytes. Blood 102:4107-4114, 2003

49. Alhamarneh $O$, Amarnath SM, Stafford ND, et al: Regulatory T cells: What role do they play in antitumor immunity in patients with head and neck cancer? Head Neck 30:251-261, 2008

50. Ralainirina $N$, Poli $A$, Michel $T$, et al: Control of NK cell functions by $\mathrm{CD} 4+\mathrm{CD} 25+$ regulatory $\mathrm{T}$ cells. J Leukoc Biol 81:144-153, 2007

51. Strauss L, Bergmann C, Szczepanski M, et al: A unique subset of CD4+CD25highFoxp3+ T cells secreting interleukin-10 and transforming growth factor-beta1 mediates suppression in the tumor microenvironment. Clin Cancer Res 13:43454354, 2007

52. Strauss L, Bergmann $C$, and Whiteside $T L$ : Functional and phenotypic characteristics of CD4+CD25highFoxp3+ Treg clones obtained from peripheral blood of patients with cancer. Int J Cancer 121:2473-2483, 2007

53. Sakakura K, Chikamatsu K, Takahashi K, et al: Maturation of circulating dendritic cells and imbalance of T-cell subsets in patients with squamous cell carcinoma of the head and neck. Cancer Immunol Immunother 55:151-159, 2006

54. Chikamatsu K, Sakakura K, Whiteside TL, et al: Relationships between regulatory $T$ cells and $\mathrm{CD} 8+$ effector populations in patients with squamous cell carcinoma of the head and neck. Head Neck 29:120-127, 2007

55. Komohara $Y$, Jinushi $M$, Takeya M: Clinical significance of macrophage heterogeneity in human malignant tumors. Cancer Sci 105:1-8, 2014

56. Lathers DM, Young MR: Increased aberrance of cytokine expression in plasma of patients with more advanced squamous cell carcinoma of the head and neck. Cytokine 25:220-228, 2004

57. O'Brien PM, Saveria Campo M: Evasion of host immunity directed by papillomavirus-encoded proteins. Virus Res 88:103-117, 2002

58. Stanley M: Immunobiology of HPV and HPV vaccines. Gynecol Oncol 109:S15-21, 2008

59. Bhat P, Mattarollo SR, Gosmann C, et al: Regulation of immune responses to HPV infection and during HPV-directed immunotherapy. Immunol Rev 239:85-98, 2011

60. Gildener-Leapman N, Ferris RL, and Bauman JE: Promising systemic immunotherapies in head and neck squamous cell carcinoma. Oral Oncol 49:1089-1096, 2013

61. Madkan VK, Cook-Norris RH, Steadman MC, et al: The oncogenic potential of human papillomaviruses: A review on the role of host genetics and environmental cofactors. Br J Dermatol 157:228241, 2007

62. Quezada SA, Peggs KS: Exploiting CTLA-4, PD-1 and PD-L1 to reactivate the host immune response against cancer. $\mathrm{Br} J$ Cancer 108:15601565, 2013

63. Lyford-Pike S, Peng S, Young GD, et al: Evidence for a role of the PD-1:PD-L1 pathway in immune resistance of HPV-associated head and neck squamous cell carcinoma. Cancer Res 73: 1733-1741, 2013

64. Badoual C, Hans S, Merillon N, et al: PD-1expressing tumor-infiltrating $\mathrm{T}$ cells are a favorable prognostic biomarker in HPV-associated head and neck cancer. Cancer Res 73:128-138, 2013

65. King EV, Ottensmeier $\mathrm{CH}$, Thomas GJ: The immune response in HPV oropharyngeal cancer. Oncoimmunology 3:e27254, 2014

66. Nasman A, Romanitan M, Nordfors C, et al: Tumor infiltrating CD8+ and Foxp3+ lymphocytes correlate to clinical outcome and human papillomavirus (HPV) status in tonsillar cancer. PLoS One 7:e38711, 2012

67. Stanley M, Pinto LA, Trimble C: Human papillomavirus vaccines: Immune responses. Vaccine 30:F83-F87, 2012 (Suppl 5)

68. Schiller JT, Castellsague X, Garland SM: A review of clinical trials of human papillomavirus prophylactic vaccines. Vaccine 30:F123-F138, 2012 (Suppl 5)

69. Steinau M, Saraiya M, Goodman MT, et al: Human papillomavirus prevalence in oropharyngeal cancer before vaccine introduction, United States. Emerg Infect Dis 20:822-828, 2014

70. Kreimer AR: Reduced prevalence of oral human papillomavirus (HPV) 4 years after bivalent HPV vaccination in a randomized clinical trial in Costa Rica. PLoS One 8:e68329, 2013

71. Sewell DA, Pan ZK, Paterson Y: Listeria-based HPV-16 E7 vaccines limit autochthonous tumor growth in a transgenic mouse model for HPV-16 transformed tumors. Vaccine 26:5315-5320, 2008

72. Davidson EJ, Faulkner RL, Sehr $P$, et al: Effect of TA-CIN (HPV 16 L2E6E7) booster immunisation in vulval intraepithelial neoplasia patients previously vaccinated with TA-HPV (vaccinia virus encoding HPV 16/18 E6E7). Vaccine 22:2722-2729, 2004

73. Albarran YCA, de la Garza A, Cruz Quiroz BJ, et al: MVA E2 recombinant vaccine in the treatment of human papillomavirus infection in men presenting intraurethral flat condyloma: A phase I/II study. BioDrugs 21:47-59, 2007

74. Brun JL, Dalstein V, Leveque J, et al: 2011. Regression of high-grade cervical intraepithelial neoplasia with TG4001 targeted immunotherapy. Am J Obstet Gynecol 204:169.e161-e168

75. Schuler PJ, Harasymczuk M, Visus C, et al: Phase I dendritic cell p53 peptide vaccine for head and neck cancer. Clin Cancer Res 20:2433-2444, 2014

76. Weise JB, Csiszar K, Gottschlich S, et al: Vaccination strategy to target lysyl oxidase-like 4 in dendritic cell based immunotherapy for head and neck cancer. Int J Oncol 32:317-322, 2008 
77. Ferris $R L$, Jaffee $E M$, Ferrone $S$ : Tumor antigen-targeted, monoclonal antibody-based immunotherapy: Clinical response, cellular immunity, and immunoescape. J Clin Oncol 28:4390-4399, 2010

78. Yewale C, Baradia D, Vhora I, et al: Epidermal growth factor receptor targeting in cancer: A review of trends and strategies. Biomaterials 34:86908707, 2013

79. Rubin Grandis J, Melhem MF, Gooding WE, et al: Levels of TGF-alpha and EGFR protein in head and neck squamous cell carcinoma and patient survival. J Natl Cancer Inst 90:824-832, 1998

80. Lopez-Albaitero A, Lee SC, Morgan S, et al: Role of polymorphic Fc gamma receptor IIla and EGFR expression level in cetuximab mediated, NK cell dependent in vitro cytotoxicity of head and neck squamous cell carcinoma cells. Cancer Immunol Immunother 58:1853-1864, 2009

81. Taylor C, Hershman D, Shah N, et al: Augmented HER-2 specific immunity during treatment with trastuzumab and chemotherapy. Clin Cancer Res 13:5133-5143, 2007

82. Lee SC, Srivastava RM, Lopez-Albaitero A, et al: Natural killer (NK): Dendritic cell (DC) cross talk induced by therapeutic monoclonal antibody triggers tumor antigen-specific $\mathrm{T}$ cell immunity. Immunol Res 50:248-254, 2011

83. Srivastava RM, Lee SC, Andrade Filho PA, et al: Cetuximab-activated natural killer and dendritic cells collaborate to trigger tumor antigen-specific T-cell immunity in head and neck cancer patients. Clin Cancer Res 19:1858-1872, 2013

84. Ramsay AG: Immune checkpoint blockade immunotherapy to activate anti-tumour T-cell immunity. Br J Haematol 162:313-325, 2013

85. Leach DR, Krummel MF, Allison JP: Enhancement of antitumor immunity by CTLA-4 blockade. Science 271:1734-1736, 1996

86. Hodi FS, O'Day SJ, McDermott DF, et al: Improved survival with ipilimumab in patients with metastatic melanoma. N Engl J Med 363:711-723, 2010
87. Hamid O, Robert C, Daud A, et al: Safety and tumor responses with lambrolizumab (anti-PD-1) in melanoma. N Engl J Med 369:134-144, 2013

88. Topalian SL, Drake CG, Pardoll DM: Targeting the PD-1/B7-H1(PD-L1) pathway to activate anti-tumor immunity. Curr Opin Immunol 24:207-212, 2012

89. Topalian SL, Hodi FS, Brahmer JR, et al: Safety, activity, and immune correlates of anti-PD-1 antibody in cancer. N Engl J Med 366:2443-2454, 2012

90. Callahan MK, Wolchok JD: At the bedside: CTLA-4- and PD-1-blocking antibodies in cancer immunotherapy. J Leukoc Biol 94:41-53, 2013

91. Li J, Jie HB, Lei $Y$, et al: PD-1/SHP-2 inhibit Tc1/Th1 phenotypic responses and the activation of $\mathrm{T}$ cells in the tumor microenvironment. Cancer Res 75:508-518, 2015

92. Jie HB, Schuler PJ, Lee SC, et al: CTLA-4+ regulatory $T$ cells increased in cetuximab-treated head and neck cancer patients, suppress NK cell cytotoxicity and correlate with poor prognosis. Cancer Res 75:2200-2210, 2015

93. Akbay EA, Koyama $S$, Carretero J, et al: Activation of the PD-1 pathway contributes to immune escape in EGFR-driven lung tumors. Cancer Discov 3:1355-1363, 2013

94. Melero I, Hirschhorn-Cymerman D, MoralesKastresana A, et al: Agonist antibodies to TNFR molecules that costimulate $T$ and NK cells. Clin Cancer Res 19:1044-1053, 2013

95. Stephenson RM, Lim CM, Matthews M, et al: TLR8 stimulation enhances cetuximab-mediated natural killer cell lysis of head and neck cancer cells and dendritic cell cross-priming of EGFR-specific CD8+ T cells. Cancer Immunol Immunother 62: 1347-1357, 2013

96. Seiwert TY, Burtness B, Weiss J, et al: A phase lb study of MK-3475 in patients with human papillomavirus (HPV)-associated and non-HPVassociated head and neck $(\mathrm{H} / \mathrm{N})$ cancer. J Clin Oncol 32:386s, 2014 (abstr 6011)

97. Vermorken, JB, Mesia R, Vega-Villegas ME, et al: Cetuximab in combination with cisplatin or carboplatin and 5-fluorouracil (5-FU) in the first-line treatment of patients with recurrent and/or metastatic squamous cell carcinoma of the head and neck (R\&M SCCHN) (EXTREME). J Clin Oncol 24: 289s, 2006 (abstr 5537)

97a. Segal NH: Safety and efficacy of MEDI4736, an anti-PD-L1 antibody, in patients from a squamous cell carcinoma of the head and neck (SCCHN) expansion. J Clin Oncol 33:150s, 2015 (suppl; abstr 3011) cohort

98. Demaria S, Kawashima N, Yang AM, et al: Immune-mediated inhibition of metastases after treatment with local radiation and CTLA-4 blockade in a mouse model of breast cancer. Clin Cancer Res 11:728-734, 2005

99. Dewan $M Z$, Galloway $A E$, Kawashima N, et al: Fractionated but not single-dose radiotherapy induces an immune-mediated abscopal effect when combined with anti-CTLA-4 antibody. Clin Cancer Res 15:5379-5388, 2009

100. Verbrugge I, Hagekyriakou J, Sharp LL, et al: Radiotherapy increases the permissiveness of established mammary tumors to rejection by immunomodulatory antibodies. Cancer Res 72:3163-3174, 2012

101. Zeng J, See AP, Phallen J, et al: Anti-PD-1 blockade and stereotactic radiation produce longterm survival in mice with intracranial gliomas. Int J Radiat Oncol Biol Phys 86:343-349, 2013

102. Postow MA, Callahan MK, Barker CA, et al: Immunologic correlates of the abscopal effect in a patient with melanoma. N Engl J Med 366:925-931, 2012

103. Stamell EF, Wolchok JD, Gnjatic $S$, et al: The abscopal effect associated with a systemic antimelanoma immune response. Int J Radiat Oncol Biol Phys 85:293-295, 2013

104. Formenti SC, Demaria S: Radiation therapy to convert the tumor into an in situ vaccine. Int J Radiat Oncol Biol Phys 84:879-880, 2012 


\section{AUTHOR'S DISCLOSURES OF POTENTIAL CONFLICTS OF INTEREST}

Immunology and Immunotherapy of Head and Neck Cancer

The following represents disclosure information provided by authors of this manuscript. All relationships are considered compensated. Relationships are self-held unless noted. I = Immediate Family Member, Inst = My Institution. Relationships may not relate to the subject matter of this manuscript. For more information about ASCO's conflict of interest policy, please refer to www.asco.org/rwc or jco.ascopubs.org/site/ifc.

\section{Robert L. Ferris}

Consulting or Advisory Role: Bristol-Myers Squibb, Merck,

AstraZeneca, CureVac, ONO Pharmaceutical, Celgene

Research Funding: Bristol-Myers Squibb (Inst), AstraZeneca (Inst),

VentiRx Pharmaceuticals (Inst) 